\title{
Community knowledge, attitudes and practices related to tick-borne relapsing fever in Dodoma Rural District, Central Tanzania
}

\author{
W.N. KISINZA ${ }^{1 *}$, A. TALBERT2 ${ }^{2}$ P. MUTALEMWA ${ }^{1}$ and P.J. MCCALL ${ }^{3}$ \\ National Institute for Medical Research, P. O. Box 9653, Dar es Salaam, Tanzania \\ ${ }^{2}$ Mvumi Hospital, Mvumi, Dodoma, Tanzania \\ ${ }^{3}$ Vector Group, Liverpool School of Tropical Medicine, Pembroke Place, Liverpool, UK
}

\begin{abstract}
Tick-borne Relapsing Fever (TBRF) is a vector-borne disease of humans which causes serious illness, primarily for children under five years old and pregnant women. Understanding people's knowledge, attitude and practices on the disease is important in designing appropriate interventions. This study was conducted to explore community knowledge, attitudes and practices regarding TBRF transmission and control to provide baseline data for the planned scaling up of intervention in Dodoma rural District in central Tanzania. A total of 198 heads of households were interviewed using a semi-structured questionnaire. Of these, $94.5 \%$ were aware of TBRF. Fever of unknown origin (69.5\%), body pain (8.5\%), headache $(8.5 \%)$, chills (4.5\%) and vomiting $(3.5 \%)$ were the most commonly mentioned symptoms. The domestic tick-infestation and tickbites was known to $82.8 \%$. High domestic tick infestation reported to occur during dry season (85.4\%). The majority believed that the disease spreads through tick-bites (85.9\%). Regular plastering of house floors and walls was the most common method used by the community to control domestic tick infestation (96.5 $\%)$. Majority $(84.3 \%)$ of the respondents preferred public healthcare facilities for treatment. Only a small proportion $(15.7 \%)$ preferred using traditional medicines. Poor knowledge of the study subjects about the disease and its control underscores the need for health educational campaigns if any control and/or elimination programme is to succeed.
\end{abstract}

Key words: tick-borne relapsing fever, knowledge, transmission, symptoms, prevention, Tanzania

\section{Introduction}

Tick-borne Relapsing Fever (TBRF) is an important public health problem in $20 \%$ of the districts of Tanzania. The disease is endemic in central, north-western and south-western parts of the country (Barclay \& Coulter, 1990; Magesa et al., 2001; Kisinza et al., 2004; Kisinza, 2006; Talbert, 2005).

A number of studies have shown that TBRF is an important endemic disease is central Tanzania. TBRF is endemic in Dodoma rural district with an annual incidence of 384 and 163 per 1,000 for children under 1 and 5 years, old respectively (Barclay \& Coulter, 1990). Infant mortality and pregnancy interruption rates are as high as $8 \%$ and $30 \%$ respectively (Talbert et al., 1998). Prevalence of TBRF infection has been recorded at 5\% and $7.5 \%$ for the febrile under five years children and pregnant women respectively (Kisinza, et al., 2003). House infestations with the Ornithodoros sp. tick vectors are high up to $88 \%$ (Talbert et al., 1998 \& Kisinza, 2006) and Borrelia sp. infection rates in these ticks is over 60\% (Fugunaga et al., 2001).

Community participation and involvement of the affected population are often considered the most important prerequisite for the success of prevention and control programmes of any disease (Alilio et al., 1998; Kengeya-Kayondo et al., 1994; Winch et al., 1992). Programme implementers need to understand the disease-related knowledge, attitudes, and practices of the community which are important determinants of community participation (Singh et al., 2006). The main objective of this study was to explore people's knowledge, attitudes, practices and behaviours regarding TBRF transmission and control to provide baseline data for the planned scaling up of insecticide treated nets coverage in Dodoma District, Tanzania. Specifically, the study aimed to determine (i) household structure and sleeping arrangements, (ii) level of knowledge of the cause and transmission of TBRF, and (iii) perceptions and practices as regards to TBRF symptoms, prevention and health seeking behaviour.

\footnotetext{
* Correspondence: Dr. William N. Kisinza; E-mail: wkisinza@nimr.or.tz
} 


\section{Materials and Methods}

\section{Study area}

This study was carried out in Dodoma rural district $\left(6^{\circ}\right.$, $30^{\prime}$ to $8^{\circ} 0^{\prime} \mathrm{S}, 35^{\circ}, 30^{\prime}$ to $37^{\circ} 0^{\prime} \mathrm{E}$ ) in central Tanzania. The district is made up of 8 divisions, 48 wards, and 128 villages covering an area of 14,004 sq km. The district population is 495,176 made up of 96,686 households. It is served by 81 health facilities ( 1 hospital, 6 health centres and 73 dispensaries). The district has a dry savannah type of climate characterized by a long dry season lasting between April and November. The average annual rainfall is $500-800 \mathrm{~mm}$, which is normally a short single wet season lasting between December and March. Temperature in the district varies according to altitude but generally the average maximum and minimum is $31^{\circ} \mathrm{C}$ and $18^{\circ} \mathrm{C}$ respectively (Mboera et al., 2007).

The study was conducted between October and November 2002 and involved households in Muungano village ( $\left.6^{\circ} 37^{\prime} 0 \mathrm{~S}, 37^{\circ} 16^{\prime} \mathrm{OE}\right)$. The village is located approximately $12 \mathrm{~km}$ Northern-east of Mvumi Hospital, $40 \mathrm{~km}$ south-east of Dodoma Municipality. The village population is approximately 7,500 people, distributed in 15 hamlets with 1,667 households (URT, 2003). The village was selected for the study as it had no history of ITN usage or of any major anti-tick measures being undertaken.

\section{Study design}

A community cross-sectional study was conducted in Muungano village among heads of households who were randomly selected. Data were collected using a pre-tested semi-structured questionnaire. The study involved 200 face-to-face interviews with heads of households (males and females) in Muungano village aged 18 years and above. Heads of households were purposively involved in the study because they are at the hub of decision making at the household level. A household was defined as residential unit with one or more individuals in occupation. Multiple families residing in the same household as well as multiple structures within a compound occupied by the dependants of household head were also considered as one household.

As community's knowledge related to TBRF was not known, the maximum sample size was calculated basing on the assumption that at least $50 \%$ of heads of households had knowledge on TBRF. The sample of heads of households was calculated using the formula: $n=1.96 P(1-P) / e$ (Moore \& McCabe, 1999), where $n$ is the sample, $P$ is the expected proportion of heads of households who had TBRF knowledge and $e$ is the error of the estimate $( \pm 10 \%)$. The sample $n$ was multiplied by 2 because of the design effect associated with cluster sampling and this led to a sample size of 192 heads of households to be interviewed. Because of expected drop-out of study subject; we therefore added $4 \%$ of the sample size, making a total sample size of 200.

All households were listed and assigned numbers. Using a simple random method, a total of 200 heads of households were selected to the study. Demographic characteristics of respondents were recorded and people were interviewed on the major health problems in their households and knowledge related to TBRF transmission, symptoms and prevention. They were also asked on infestations and tick-bites, strategies used to control domestic tick infestations, health seeking behaviour and on animals keeping practices. Exploration and physical observations were also made of the type of house and household sleeping arrangements (including use of raised beds and insecticide treated mosquito nets). Questionnaires were pre-tested in Mvumi village henceforth refined in order to test their validity, precision and consistency. Interviews were conducted in Kiswahili (the National language).

\section{Data analysis}

Before data entry and analysis questionnaires were checked for coding errors, completeness and consistency. Data were entered in the computer using Epi-Info data processing package and analyzed using Statistical Package for Social Sciences (SPSS for windows, version 11.0, Chicago, USA).

\section{Ethical considerations}

The Research Ethics Committees of the Tanzanian National Institute for Medical Research and Liverpool School of Tropical Medicine granted ethical and scientific clearance/approval. Informed consents were obtained from the interviewees before conducting the survey.

\section{Results}

Of the 200 selected households, 198 (99\%) participated in interviews and two of them dropped out. The male: female ratio was 1.13:1. The mean age of the respondents was $44 \pm 26$ years (range $=18-70$ years). More than half of the study population was illiterate $(64.1 \%)$, while $35.9 \%$ had a primary school education. Their main occupation was subsistence farming (95\%) of cassava, finger millet and groundnut. Other occupations included carpentry (1.5\%), vendors/retailers (3.5\%). Most of the households kept chickens (62.6\%), pigs (35.4\%) and cattle/goats (2\%). 
Table 1: Socio-demographic characteristics of the study population in Muungano village

\begin{tabular}{|c|c|c|c|}
\hline \multirow{2}{*}{ Characteristics $(\mathrm{N}=198)$} & \multirow{2}{*}{ Categories } & \multicolumn{2}{|c|}{ Study population } \\
\hline & & Number & Percentage \\
\hline \multirow[t]{2}{*}{ Sex } & Male & 93 & 47.0 \\
\hline & Female & 105 & 53.0 \\
\hline \multirow[t]{3}{*}{ Age (years) } & $18-24$ & 35 & 17.7 \\
\hline & $25-44$ & 105 & 53.0 \\
\hline & $45+$ & 58 & 29.3 \\
\hline \multirow[t]{2}{*}{ Household size } & $4-6$ & 113 & 57.1 \\
\hline & $\geq 7$ & 85 & 42.9 \\
\hline \multirow[t]{2}{*}{ Educational status } & Primary School & 71 & 35.9 \\
\hline & Illiterate & 127 & 64.1 \\
\hline
\end{tabular}

Only $22(11 \%)$ households had raised beds and only 8 (4\%) households had insecticide treated mosquito nets. A total of 194 (98\%) households had traditional style mud houses with flat roofs known as 'tembe'. These houses were of two categories, namely households with hard and plastered floors $(89 ; 45 \%)$ and those with loose floors and walls not rendered with mud $(109 ; 55 \%)$. problems included pneumonia, eye infections and abdominal pain accounted (3\%).

The majority $(82.83 \%)$ of the respondents reported to have had domestic tick infestations and experienced tickbites in their households. High domestic tick infestation was during dry season. And minority (2.53\%) reported

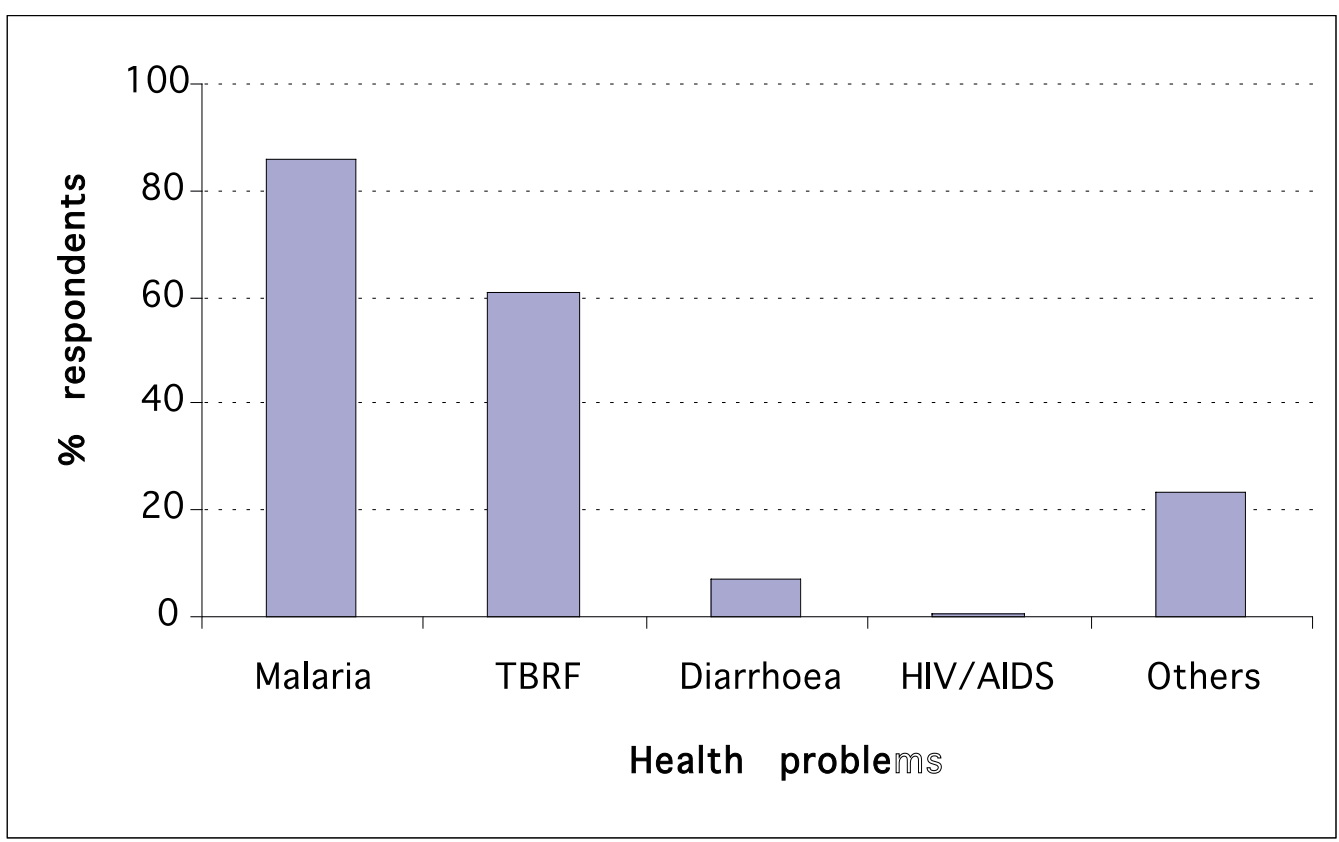

Figure 1: Community ranking of major health problems in their households

Of the total respondents, 170 (85.9\%) cited that malaria as the most important public health problem in the village. This was followed by tick-borne relapsing fever, diarrhoea and HIV/AIDS (Figure 1). Other health to have had domestic tick infestations all year round. While majority of respondents $(85.86 \%)$ cited that TBRF is transmitted by the bite of soft ticks, few reported that disease is transmitted by mosquito bites (Table 2). 
Table 2: Knowledge about domestic tick infestations, bites and TBRF transmission

\begin{tabular}{lcc}
\hline & Number of responses (N=198) & Percentage \\
\hline Domestic tick infestations & 164 & 82.83 \\
$\quad$ Infestations during dry season & 140 & 85.37 \\
infestations during wet seasons & 19 & 11.59 \\
Infestations all year round & 5 & 0.30 \\
Cause of TBRF & 170 & \\
Tick bites & 10 & 85.86 \\
Mosquito bites & 4 & 5.05 \\
Other insect bites (Bedbugs and Fleas) & 14 & 2.02 \\
Don't know & 14 & 7.10 \\
\hline
\end{tabular}

The mostly mentioned symptom of TBRF was fever $(69.5 \%)$. Other symptoms mentioned included joint and muscle pains $(8.5 \%)$, headache $(8.5 \%)$, chills $(4.5 \%)$, diarrhoea (4.5\%) and vomiting (3.5\%). The majority $(84.3 \%)$ of the respondents sought treatment from the nearest healthcare facilities, whereas, $2 \%$ sought services from traditional practitioners. About $12.1 \%$ used self-medication at home either using local herbs, of which $9.1 \%$ obtained the drugs from drug stores or shops. Three $(1.5 \%)$ respondents did nothing to treat an episode of suspected TBRF.

Majority of respondents $(96.46 \%)$ reported to have plastered their house floors and walls regularly to control domestic tick-infestations. Others poured or sprinkled hot water on the walls and floors of their houses to kill ticks or used insecticides to control domestic tick infestations in their households.

Table 3: Control methods by community members form domestic tick infestations

\begin{tabular}{lll}
\hline Variable & $\begin{array}{l}\text { No. Responses } \\
(\mathbf{N = 1 9 8 )}\end{array}$ & Percentage \\
\hline Plastering the house floor \& walls & 191 & 96.5 \\
Sprinkling hot water & 34 & 17.2 \\
Sweeping the house regularly & 158 & 79.8 \\
Used insecticides other than ITNs & 41 & 20.7 \\
Use of bednets (untreated bednets) & 8 & 4.0 \\
\hline
\end{tabular}

\section{Discussion}

Results indicated that TBRF is considered to be one of the most public health problems in the area. TBRF has been endemic disease in the region (Barclay \& Coulter, 1990) with domestic tick infestations as high as $88 \%$ (Talbert et al., 1998). Domestic tick infestation was cited by majority of respondents to be high. This probably has been attributed by factors such as poverty. The majority of people in the area were subsistence peasants who could not afford modern houses. Most of the houses (98\%) in the areas were typical traditional style ('tembe), which provides suitable harbourage for domestic tick infestations. Similar findings have been reported in Meru, Kenya where traditional African houses were found to be highly tick infested compared to the modern houses (Walton, 1962). Many people in Dodoma rural sleep on the floor on mats prepared from hides or skins making them easy target for the nocturnal ticks harbouring in earth floors.

Knowledge about transmission and clinical symptoms of TBRF was well articulated by majority of respondents. Knowledge of TBRF might have been imparted to people seeking medical treatment at health facilities or during antenatal clinic services.

The habit of indoor keeping of animals proximate to the human habitations particularly chickens and pigs possibly creates high risks of domestic infestations as these animals have been shown to be both alternative 
hosts for ticks and reservoirs of Borrelia spp (Motshegwa, 2004; McCall et al., 2007). It has been also reported that keeping animals indoors encourages domestic tick infestations (Walton, 1964). Our findings showed that domestic tick infestation occurs throughout the year with different infestation rates at different seasons; corresponding to previous findings in other parts of East Africa (Walton, 1964).

Treatment-seeking behaviour is related to cultural beliefs about the cause and cure of illness (Oberlander et al., 2000; Makundi et al., 2006). Commonly people starts care for a sick relative at home with what is available (herbs, remaining drugs, drugs from shops, and only seek medical advice when there is no response or the condition deteriorates. In this study few people sought medical treatment from traditional healers, possibly because they had no money to meet the expected cost of treatment at health facility. Treatment-seeking behaviour from traditional practitioners might one of the reasons for getting incorrect medical treatment for TBRF related illnesses. Advocacy is needed to change people's health seeking behaviour from self-medication to early diagnosis and prompt treatment from health facilities. Self-treatment and traditional medicine are habitual among the population in Tanzania (Tarimo et al., 2000, Makundi et al., 2006). This calls for behavioural change intervention.

There have been efforts to control TBRF in Dodoma in the recent years. Insecticide treated mosquito nets have been found to protect against tick bites and householders (Kisinza, 2006). Some householders have used deltamethrin, supplied in net treatment kits, diluted with water, to sprinkle on the floor and walls (Kisinza et al., 2004) to render them smooth and eliminate the cracks where ticks prefer to hide. These methods were not effective as domestic tick infestations continued to exist. The long-term solution would be to improve housing condition. Improved house condition has long been believed to reduce domestic tick infestations (Walton, 1964). However, many families are unable to afford the costs of cement and corrugated iron for house construction. Moreover, the local community prefers traditional "tembe" houses which are cooler even during hot weather.

In conclusion, TBRF has been perceived as a major public health problem and majority of people are knowledgeable of the mode transmission and symptoms of the disease. However, the incorrect treatment-seeking behaviour related to TBRF observed in this study calls for appropriate public health education programmes in endemic areas. Insecticide treated nets coupled with appropriate community based- interventions such im- proving housing condition and living standards of people through health awareness campaigns, have the potential to reduce TBRF transmission in the region.

\section{Acknowledgements}

The authors thank the people in the study village for their enthusiasm in the study. We are most grateful to Mr. Stafford Sanya and Adam Chuih for their excellent field assistance. The study was funded by a grant from the Sir Halley Stewart Trust UK.

\author{
Received 24 April 2008 \\ Revised 2 June 2008 \\ Accepted 17 June 2008
}

\section{References}

Alilio, M., Bammek, J. \& Eversole, H. (1998) A KAP Study on malaria in Zanzibar: implications for prevention and control. A study conducted for UNICEF Sub-Office Zanzibar. Evaluation and Program Planning 21, 409-413

Barclay, A.J.G. \& Coulter, B.S. (1990) Tick-borne relapsing fever in central Tanzania. Transactions of the Royal Society of Tropical Medicine and Hygiene 84, 852-856

Fukunaga, M, Ushijima, Y \& Talbert, A. (2001) Detection of Borrelia duttonii, a Tick-Borne Relapsing Fever Agent in Central Tanzania within Ticks by Flagellin Gene-Based Nested Polymerase Chain Reaction. Vector Borne and Zoonotic Diseases, 1(4): 331 - 338

Kengeya-Kayondo, J.F., Seeley, J.A., Kajura-Bajenja, E., Kabunga, E., Mubiru, E., Sembajja, F. \& Mulder, D.W. (1994) Recognition, treatment-seeking behaviour and perception of cause of malaria among rural women in Uganda. Acta Tropica 58, 267-273.

Kisinza, W.N, McCall PJ, Mitani H, Talbert A, Fukunaga M (2003). A newly identified tick-borne Borrelia species and relapsing fever in Tanzania. Lancet $362,1283-1284$.

Kisinza, W.N. (2006) Natural History of Ornithodoros and Vector Control of Tick-Borne Relapsing Fever in Tanzania. Ph.D. Thesis, University of Liverpool, United Kingdom.

Kisinza, W.N., Talbert, A., Cutler, S., Siza, J., Jessey, P., Raymond, V. \& McCall, P.J. (2004). Epidemiology and control of tick-borne relapsing fever in Africa: the past, present and future research perspectives. Tanzania Health Research Bulletin 6, 5-10. 
Magesa, S.M., Mboera, L.E.G., Mwisongo, A.J., Kisoka, W.J., Mubyazi, G.M., Malebo, H., Senkoro, K.P., Mcharo, J., Makundi, E.A., Kisinza, W.N., Mwanga, J., Mushi, A.K., Hiza, P., MalecelaLazaro, M.N. \& Kitua A.Y. (2001) Major health problems in some selected districts of Tanzania. Tanzania Health Research Bulletin 3, 10-14.

Makundi, E., Malebo, H., Mhame, P., Kitua, A. \& Warsame, M. (2006) Role of traditional healers in the management of severe malaria among children below 5 years of age: the case of Kilosa and Handeni Districts, Tanzania. Malaria Journal 5, 58.

Mboera, L.E.G., Rumisha, S.F., Senkoro, K.P., Mayala, B.K., Shayo, E.H. \& Kisinza, W.N. (2007) Knowledge and health information communication in Tanzania. East African Journal of Public Health 4, 33-39.

McCall, P.J., Hume, J.C., Motshegwa, K., Pignatelli, P., Talbert, A. \& Kisinza, W. (2007) Does TBRF have an animal reservoir in East Africa? Journal of Vector-Borne and Zoonotic Diseases 7, 1-8.

Moore, D. \& McCabe, G. (1999) Introduction to the Practice of Statistics (3rd Edition). New York: W.H. Freeman and Company.

Motshegwa, K. (2004) Screening Domestic Pigs and Chickens for Tick-borne Relapsing Fever Agent (Borrelia sp.) in Central Tanzania. MSc. Thesis, Liverpool School of Tropical Medicine, UK.

Oberlander L \& Elverdan B (2000). Malaria in the United Republic of Tanzania: Cultural considerations and health seeking behaviour. Bulletin of World Health Organisation 78, 1352 - 1357.

Singh, S.P., Reddy, D.C.S., Mishra, R.N. \& Sundra, S. (2006) Knowledge, attitudes, and practices related to Kala-Azar in a rural area of Bihar State, India. American Journal of Tropical Medicine and Hygiene 75, $505-508$.
Talbert, A. (2005) Tick-borne relapsing fever in Mvumi Hospital, between 1997 and 2005 Tanzania: a retrospective study of laboratory data. Tanzania Health Research Bulletin 7, 40-42.

Talbert, A., Nyange, A. \& Molteni, F. (1998) Spraying tick-infested houses with lambdacyhalothrin reduce the incidence of tick-borne relapsing fever in children under five years old. Transactions of Royal Society of Tropical Medicine and Hygiene, 92, 251-253.

Tarimo, D.S., Lwihula, G.K., Minjas, J.N., Bygbjerg, I.C. \& Mother, S. (2000) Perceptions and knowledge on childhood malaria in the holoendemic Kibaha district, Tanzania: implications for malaria control and the IMCI strategy. Transactions of Royal Society of Tropical Medicine and Hygiene, 5, 179-184.

URT (2003) National Population and Housing Census Report, 2002. United Republic of Tanzania.

Walton, G. A. (1962) The Ornithodoros moubata super-species problem in relation to human relapsing fever epidemiology. In: Aspects of Disease Transmission by Ticks. Cork, D.R. A. Symposia of the zoological society of London, No. 6, 83-156

Walton, G.A. (1964) The Ornithodorus "moubata" group of ticks in Africa. Control problems and implications. Journal of Medical Entomology, 1, 53-64.

Walton, G.A.(1979) A taxonomic review of the Ornithodoros moubata (Murray). Recent Advances in Acarology 2, 491 -500.

Winch, P., Kendall, C. \& Gubler, D. (1992) Effectiveness of community participation in vector-borne diseases control. Health Policy and Planning 7, $342-351$. 